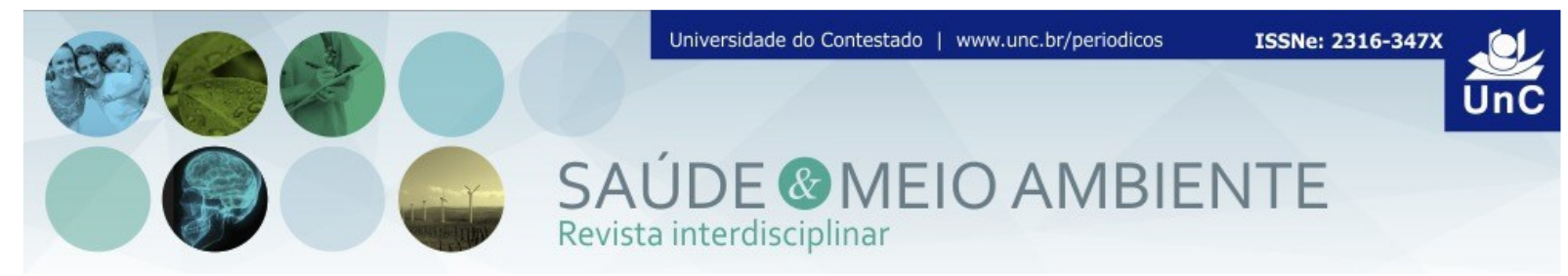

\title{
CONSTRUÇÃO DE BRINQUEDOS NAS AULAS DE EDUCAÇÃO FÍSICA: EDUCAÇÃO AMBIENTAL ${ }^{1}$
}

\author{
Vinicius Aparecido Galindo ${ }^{2}$ \\ Cinthia Lopes da Silva ${ }^{3}$
}

\begin{abstract}
RESUMO
O objetivo deste texto é analisar os significados do brincar e da construção de brinquedos para crianças do Ensino Fundamental em uma situação planejada de oficina-aula de construção de brinquedos com materiais recicláveis, em uma perspectiva cultural articulada com a Educação Física Plural em interface com a educação ambiental. As crianças, ao serem incentivadas ao consumo de produtos que incluem os brinquedos, os jogos e objetos eletrônicos, podem não ter a oportunidade de refletir sobre eles tanto quanto ao construir brinquedos, criar novas maneiras de brincar no seu "tempo livre" e se conscientizar sobre questões relacionadas ao meio ambiente (consumo, reciclagem, preservação). Neste estudo, realizou-se pesquisa bibliográfica e de campo, de tipo participante, constituindo-se em uma investigação de abordagem qualitativa. A proposta pedagógica do professor, oficina-aula, teve como estratégia a participação das crianças na dinâmica dessas atividades diversificadas, aguçando a curiosidade e o interesse de todos. Para a realização dessas oficinas-aulas foram utilizados materiais recicláveis como matéria-prima na produção dos brinquedos. Construir e brincar envolve cooperação, criatividade, preservação, reflexão e habilidades motoras, tão importantes para a formação do cidadão. Conclui-se que as crianças gostaram de brincar pelo fato de serem brinquedos construídos com materiais recicláveis. Além disso, as atividades estimularam a conscientização sobre a valorização do meio ambiente.
\end{abstract}

Palavras chave: Educação Física escolar. Educação Ambiental. Construção de Brinquedos. Ensino Fundamental I.

\footnotetext{
${ }^{1}$ Este trabalho é recorte de uma pesquisa maior, em nível de mestrado, desenvolvida em uma Universidade no interior do estado de São Paulo.

${ }^{2}$ Graduado em Educação Física, Mestre em Ciências do Movimento Humano, e também docente na instituição de ensino superior: Centro Universitário do Norte Paulista (UNORP). Lecionando nas disciplinas Educação Física Escolar/ Lazer e Recreação; Educação Física Adaptada e Metodologia dos Esportes Alternativos e Artes Marciais. São Paulo. Brasil. E-mail: vinicius.galindo@unorp.br. ORCID: https://orcid.org/0000-0003-0123-6093

${ }^{3}$ Postgraduate Program in Human Movement Sciences. Programa de Pós-graduação em Ciências do Movimento Humano. Universidade Metodista de Piracicaba, SP (UNIMEP). Piracicaba, São Paulo. Brasil. E-mail: cinthia.silva@unimep.br
} 


\title{
TOYS CONSTRUCTION IN PHYSICAL EDUCATION CLASSES: ENVIRONMENTAL EDUCATION
}

\begin{abstract}
The purpose of this paper is to analyze the meanings of play and construction of toys for elementary school children in a planned situation of construction of toys with recyclable materials in workshop-class from an environmental education perspective. When encouraged to use products that include toys, games, technology, children may not have the opportunity to reflect on them as much as when building toys, creating new ways to play in their free time and becoming aware on environmental issues (consumption, recycling, preservation). Building and playing involves cooperation, creativity, preservation, reflection and motor skills, so important for the formation of the citizen. This study is a bibliographical and field research on a qualitative approach. The pedagogical proposal of the teacher (workshop-class) had as a strategy the participation of children in the dynamics of these diversified activities, enhancing the curiosity and interest of all. For the realization of these workshops, recyclable materials were used as raw material in the production of toys. It was concluded that children liked to play because they were toys built with recyclable materials; in addition, the activities stimulated the awareness about the valuation of the environment.
\end{abstract}

Keywords: School Physical Education. Environmental Education. Construction of Toys. Elementary School I

\section{INTRODUÇÃO}

Esta pesquisa se justifica pelo fato de as crianças serem incentivadas ao consumo de produtos industrializados, dentre eles, os brinquedos, os jogos infantis a tecnologia, sem terem, muitas vezes, a oportunidade de refletir sobre esse processo, assim como de construir brinquedos e criar novas maneiras de brincar. Nesse sentido, consideramos como fundamental que as crianças e jovens tenham acesso ao conhecimento acerca do brincar e da construção de brinquedos com material reciclável, sendo as aulas de Educação Física escolar um espaço privilegiado para isso. Além disso, representam uma oportunidade para aprofundar-se sobre questões ambientais como consumismo, reciclagem e preservação.

Com o desenvolvimento tecnológico na atualidade, os recursos eletrônicos e os brinquedos industrializados, cuja aquisição é incentivada, ou mesmo instigada pelo consumismo, permeiam a rotina das crianças, com nítido predomínio no cotidiano, o que influencia a complexidade da formação do ser humano. Segundo Castro et al. (2009), a visão de consumo vem sendo discutida no mundo moderno, já que a sociedade na qual vivemos, movida pelo sistema capitalista, isto é, a compra de bens desnecessários e em pouco tempo é incentivada pela mídia, influenciando novas aquisições. Como consequência, o consumo exagerado e o descarte de bens de consumo não duráveis têm propiciado um impacto no meio ambiente. 
Para Carvalho (2001), a educação ambiental é um processo de aprendizagem com o intuito de preservar o meio ambiente de que usufruímos e em que vivemos, buscando métodos de desenvolvimento com iniciativas sustentáveis, com o propósito de encontrar maneiras adequadas de desenvolvimento que atenda às necessidades na atualidade sem comprometer as gerações futuras. De acordo com Oliveira e Alvim (2009), a educação ambiental é considerada como conteúdo em todos os níveis de ensino, sem se constituir em disciplina específica, possibilitando hábitos e atitudes saudáveis de respeito à natureza, sensibilidade e conservação ambiental, a partir do cotidiano de vida do cidadão, da escola e da sociedade. Ou seja, a educação ambiental pode ser desenvolvida como uma dimensão da educação, ao relacionar as ações entre a sociedade e o meio ambiente, sendo, assim, fundamental para a formação do ser humano no ambiente escolar.

A Educação Física escolar, enquanto disciplina, deve estar comprometida com o desenvolvimento integral da criança, com o intuito de sistematizar a sua prática por meio de teorias do desenvolvimento humano (OLIVEIRA; ALVIM, 2009). A Educação Física é uma disciplina com capacidade de abordar, formular e discutir novos saberes, ou seja, pode relacionar seus conteúdos específicos com diferentes temáticas de relevância social, dentre elas, a educação ambiental, constituindo-se na abertura para novos caminhos em busca de transformações (LUCENTINI, 2010).

A Educação Física escolar, como prática social, poderá viabilizar às crianças o acesso ao conhecimento sobre a construção de brinquedos com material reciclável, sempre em conformidade com o contexto social em que a escola está inserida. Deve-se, ainda, ressaltar que construir brinquedos nas aulas de Educação Física poderá ter como finalidade o desenvolvimento de atitudes e valores como o respeito ao meio ambiente, o autoconhecimento, o reconhecimento e a valorização da cultura do outro, visando ao compartilhar da criatividade e da criticidade.

O brinquedo industrializado chega pronto para a criança e tem como característica a padronização. Quando alunos e alunas constroem seu próprio brinquedo, $\mathrm{o}$ objeto tem identidade própria e propicia uma aprendizagem significativa. Ou seja, o sujeito participante pode protagonizar ações por meio da manifestação lúdica, propiciando sentido e significado na sua cultura de movimento. Sobre a construção de brinquedos, Campos e Mello (2010, p. 25) nos apresentam a seguinte perspectiva:

\footnotetext{
A exigência da motricidade da criança nesse processo, que faz com que seu corpo se movimente de maneiras diferentes para poder brincar (com o brinquedo) em diferentes espaços e de várias formas, contribui para o aumento do seu repertório motor. O objeto, assim confeccionado, passa a ter significado e sentido para a criança, porque ela vivenciou todas as etapas de sua elaboração, tomou decisões, sugeriu mudanças, estabeleceu regras para poder brincar com ele, entre outras atividades imprescindíveis para o desenvolvimento de aprendizagens que a escola exige para o domínio dos conteúdos científicos trabalhados em seus currículos.
}

O aspecto motor deve ser desenvolvido na infância em uma perspectiva lúdica, valorizando o repertório que a criança já possui e aprofundando a cultura de movimento do sujeito, vinculada ao seu contexto cultural. Além disso, no processo de construção do próprio brinquedo nas aulas de Educação Física, a criança é 
participante ativa e tem acesso à origem do brinquedo, aos materiais recicláveis, e é envolvida em todo o processo de criação. De acordo com Schwartz (1992, p. 318):

[...] as crianças hoje em dia, raramente constroem seus próprios brinquedos, havendo uma perda substancial, uma desvalorização do espaço criativo, por se privilegiar o produto e a minimização do tempo e do espaço de ação.

É importante que as crianças construam seus próprios brinquedos, assim, elas poderão chegar à compreensão, com a ajuda do professor, de que a atividade de construir coisas é uma produção de sua imaginação e que todo o trabalho se constitui em dominar conhecimentos que envolvem habilidades e determinada técnica. Ao facilitar a participação efetiva da criança em todas as etapas de produção do brinquedo e permitir que ela tenha acesso ao produto final, é possível que ela desenvolva sua potencialidade para a criticidade e a criatividade.

$\mathrm{Na}$ dinâmica das atividades em oficinas-aulas ${ }^{4}$ de construção de brinquedos com material reciclável, ao criar condições para a resolução conjunta de situaçõesproblemas, o professor contribui para a formação de um ambiente facilitador à conscientização de uma visão crítica sobre o espaço em que as crianças estão envolvidas, na busca do desenvolvimento da sua autonomia para resolver problemas e modificar sua realidade social.

Segundo Pinto (2008), uma proposta da educação para o lazer na escola implica uma educação de pessoas capazes de compreender e vivenciar oportunidades diversificadas e disponíveis nos tempos e espaços, dia após dia, com condições de ressignificá-las de forma consciente. Para Marcellino (2007), uma educação para o lazer, por meio de ações educativas como forma de incentivo e com aumento da prática de atividades diversificadas, possibilita a imaginação criadora e o espírito crítico no ser humano. Valorizar a escola no sentido de uma educação para o lazer, ou seja, como um lugar de construção do saber, promove o acesso às diferentes culturas produzidas pelos seres humanos para o desenvolvimento de suas potencialidades. Professores e alunos são sujeitos da própria história e se relacionam entre si, compartilhando diferentes experiências para a disseminação da cultura em todas as esferas sociais. Nesse sentido, a educação pode contribuir para a emancipação do sujeito no desenvolvimento de suas potencialidades, ao obter uma postura crítica e autônoma com relação aos problemas de relevância social, de modo a garantir um nível cada vez mais elaborado de acesso aos conhecimentos sobre lazer e meio ambiente.

As contribuições desta pesquisa visam à melhoria da Educação Física, que está voltada para uma educação de qualidade-equidade alicerçada na escola e no desenvolvimento do conhecimento, já que essa instituição pode contribuir, efetivamente, para a formação humana em uma perspectiva da educação ambiental.

\footnotetext{
${ }^{4} \mathrm{O}$ termo "oficinas-aulas" significa neste trabalho uma ação pedagógica em contexto planejado de aulas de Educação Física que possui um caráter experimental na utilização de material reciclável em uma perspectiva da educação ambiental, para a construção de brinquedos e vivência de brincadeiras.
} 
Nota-se que, décadas atrás, a Educação Física escolar teve uma forte influência das Ciências Naturais. Valorizava-se o corpo do ser humano no seu aspecto biológico, visando o seu desempenho e rendimento, ou seja, os indivíduos mais habilidosos, de certo modo, eram privilegiados nas aulas, e os menos habilidosos eram excluídos das atividades. Segundo Daolio (1994), a Educação Física escolar é uma prática cultural com uma tradição respaldada em certos valores. Ela ocorre em certo cenário, com certo enredo e para certo público. A Educação Física escolar deve, portanto, partir do conhecimento corporal das crianças e das suas diversas formas de manifestação, e realizar uma mediação pedagógica a partir do conhecimento sistematizado, de modo a incentivar a produção cultural por parte das crianças.

A proposta de uma Educação Física plural apresentada por Daolio (1997), fundamentada em referencial cultural e vinculada ao contexto local, pode transformar a realidade das crianças que a vivenciam. Ou seja, a Educação Física escolar é um espaço privilegiado para a transformação de valores, viabilizando às crianças reflexões para além do ambiente escolar. Para isso, é fundamental que o professor reconheça e valorize a diversidade das crianças e que atue em oficinasaulas na construção de brinquedos com material reciclável, reconhecendo este como um caminho possível para o processo de aprendizagem das crianças.

Portanto, com base nos pressupostos teóricos da Educação Física plural no ambiente escolar, o professor poderá adotar novas estratégias em suas aulas, viabilizando às crianças a construção de brinquedos artesanais com material reciclável. Esta amplitude do olhar, ao buscar a humanização pedagógica, poderá facilitar as interações entre as diversas formas de cultura, respeitando a identidade cultural das crianças e potencializando as ações de todos os envolvidos no processo de aprendizagem. Assim sendo, a partir de um referencial cultural de Educação Física escolar e dos estudos do lazer e da educação ambiental, o professor de Educação Física poderá elaborar um planejamento das suas ações pedagógicas em uma proposta interdisciplinar com outras áreas (Português, Ciências, Sociologia, Filosofia) com o intuito de viabilizar às crianças o acesso a diversos conhecimentos para que possam construir seus próprios brinquedos com material reciclável, vivenciar brincadeiras diversas e aprender a partir da interação com o outro e com o meio ambiente (OLIVEIRA; ALVIM, 2009). Atividades diversificadas culturais com sentido e significado no ambiente escolar aguçam a curiosidade e o interesse de quem está vivenciando, desenvolvendo a autonomia, a criticidade e a criatividade no sujeito.

\section{PERCURSO METODOLÓGICO}

O presente texto apresenta um estudo compreendido em duas etapas: a) pesquisa bibliográfica, e b) pesquisa de campo. A pesquisa bibliográfica foi realizada no período de março de 2014 a abril de 2015, a partir das obras relativas aos termos chave relacionados entre si: "Educação Física escolar", "Educação ambiental", 
"Brinquedos", "Brincadeiras", "Lazer" e "Cultura". Com base em Severino (2007), no levantamento bibliográfico, foram consideradas as seguintes formas de análise: textual, temática, interpretativa e problematização. Deve-se ressaltar que este trabalho é de natureza qualitativa, a qual, segundo Minayo (1994), consiste numa investigação que visa a compreender o universo de significados, motivos, aspirações, crenças, valores e atitudes. Isso corresponde a um espaço mais profundo das relações, dos processos e dos fenômenos que não podem ser reduzidos à operacionalização de variáveis.

A pesquisa de campo foi desenvolvida na segunda etapa, e envolveu os conhecimentos sobre a construção de brinquedos, a educação ambiental e o brincar em oficinas-aulas de Educação Física. Inicialmente, foi solicitada permissão para os responsáveis, explicando os objetivos e os procedimentos da atividade proposta, com o intuito de sensibilizá-los para a participação de seus filhos na pesquisa.

Nessa ocasião, foram apresentados o Termo de Consentimento Livre e Esclarecido (TCLE) e o protocolo de pesquisa do projeto $n^{\circ} 87 / 2015$ aprovado pelo Comitê de Ética em pesquisa (CEP) da instituição em que o estudo foi desenvolvido, para que os responsáveis tivessem acesso às informações sobre todas as etapas da pesquisa e registrassem sua autorização em documento assinado para dela participar. Apresentamos aos pais e às crianças informações sobre as oficinasaulas, desde a coleta dos materiais recicláveis, a construção de brinquedos até as atividades ministradas nas aulas de Educação Física, e também explicamos que seria utilizado um diário de campo pelo professor-pesquisador para registrar os dados da realidade a serem interpretados e analisados posteriormente.

Toda essa etapa de pesquisa de campo foi realizada em uma escola estadual localizada na cidade de São José do Rio Preto, interior do estado de São Paulo, com crianças das séries iniciais do ensino fundamental (ciclo I), na faixa etária de 10 a 11 anos, em uma sala de 28 crianças de ambos os sexos (18 meninos e 10 meninas). A escolha do local e do público deve-se ao fato de o pesquisador atuar nessa unidade escolar diariamente como professor. As crianças foram identificadas na pesquisa pelo número de chamada. A presente proposta pedagógica foi elaborada e realizada pelo professor durante as aulas de Educação Física, com o objetivo de viabilizar às crianças o acesso a conhecimentos que permitissem aprender sobre a construção de brinquedos no ambiente escolar e sobre algumas questões relacionadas ao meio ambiente (reciclagem, consumo, preservação) e à vivência no brincar com os objetos construídos. Para a realização das oficinas-aulas teve como princípio básico a participação das crianças nas atividades, em ambiente propício a desenvolver a criatividade, a autonomia e a criticidade. Na realização dessas oficinas-aulas, foram utilizados materiais recicláveis como matéria-prima na construção dos brinquedos.

As oficinas-aulas foram organizadas pelos seguintes temas: a) "O lúdico e a socialização"; b) "A transformação dos brinquedos e brincadeiras"; c) "Os Jogos e o brincar"; d) "O lazer no tempo além da escola"; e e) "A construção de brinquedos com material reciclável nas aulas de Educação Física", e também foi realizada uma "Exposição" das atividades desenvolvidas. Na dinâmica das oficinas-aulas, utilizamos como estratégia de ensino o circuito formado por estações de materiais, 
que foi base para a construção de brinquedos com material reciclável para a vivência de algumas brincadeiras, como exemplo, a peteca e o cai-cai ${ }^{5}$.

Além da confecção dos objetos, destacamos que as oficinas-aulas tiveram como princípio a valorização do conhecimento prévio das crianças sobre a cultura corporal de movimento, respeitando os diversos tipos de culturas e diferentes manifestações corporais, e alguns aspectos relacionados ao meio ambiente e à educação ambiental, tendo como base uma Educação Física plural. Ao término do processo de aprendizagem, o professor-pesquisador investigou junto às crianças quais os significados do brincar e da construção de brinquedos. Foram feitas a eles as seguintes perguntas no final de cada oficina-aula: Vocês gostaram de construir brinquedos com material reciclável? Se sim, por que vocês gostaram? Se não, por que não gostaram? Vocês gostaram de brincar com material reciclável? Se sim, por que vocês gostaram? Se não, por que não gostaram? ${ }^{6}$

O registro das oficinas-aulas foi realizado por meio de diário de campo e gravador, instrumentos utilizados pelo professor-pesquisador com o propósito de observar, registrar, gravar e anotar dados que foram analisados e interpretados posteriormente, tendo como base o referencial estudado. Segundo Lopes da Silva (2008, p. 42), o uso do diário viabiliza a interpretação dos dados anotados:

[...] de modo a reconstruí-los, interpretando os sentidos que os participantes da pesquisa atribuem aos temas trabalhados e a ressignificação desses temas a partir de nossos encontros e confrontos de conhecimentos, da mediação de sentidos realizadas nas aulas.

A construção, a descrição e a análise das oficinas-aulas, bem como a análise dos significados do brincar e da construção de brinquedos para os alunos foram as finalidades da pesquisa. A análise foi feita tendo como base o referencial teórico estudado, centrado na Educação Física plural, educação ambiental, construção de brinquedos (material reciclável), no brincar e na educação para o lazer. Foram também feitas observações gerais durante a realização das oficinas-aulas e, para isso, tivemos como base a técnica de observação participante, de acordo com Bruyne et al. (1991), pressupondo convívio com os sujeitos a serem observados. No primeiro momento em que as atividades estavam acontecendo nas oficinas-aulas, o professor-pesquisador adotou uma postura de observador, relatando, no diário de campo e com o auxílio de um gravador, os fatos ocorridos e, no final da aula, os alunos foram reunidos, ocasião na qual o professor-pesquisador fez uma roda de conversa com o intuito de fazer perguntas para buscar mais dados da realidade. Já no segundo momento, foi feita a descrição das oficinas-aulas, juntamente com a interpretação e a transcrição dos fatos. Para a descrição das oficinas-aulas,

\footnotetext{
${ }^{5}$ Cai-cai é um brinquedo construído com duas garrafas pet que foram adequadamente cortadas. De uma delas, retirou-se a base. A garrafa pet cortada ao meio abriga a metade de outra garrafa com a boca voltada para baixo sem a tampa, afixada com fita adesiva, de tal forma que se distancie um palmo da mão do fundo da primeira garrafa, onde deverão se acumular as bolinhas de gude introduzidas pela boca da metade da primeira garrafa. O objetivo do jogo é passar todas as bolinhas contidas na base da primeira garrafa pelo obstáculo da boca destampada da garrafa superior, por onde elas entraram.

${ }^{6}$ Essas perguntas foram adaptadas a partir do objetivo da investigação, de modo a facilitar a comunicação com as crianças.
} 
seguiremos a divisão: 1) parte inicial (em que é relatado o que foi proposto aos alunos); 2) observações gerais (como a oficina-aula aconteceu, o que pode ser observado); 3) parte final (como a oficina-aula foi concluída; nesse momento, foram feitas as perguntas da pesquisa aos alunos); e 4) análise da oficina-aula (momento em que é feita a análise da oficina-aula, assim como dos significados do brincar e da construção de brinquedos para os alunos participantes da pesquisa, tendo como base o referencial teórico estudado). As respostas dos alunos que fizeram parte da pesquisa foram de manifestação espontânea quando o professor-pesquisador fez as perguntas, e essas respostas são blocos que o professor-pesquisador construiu, aglutinando devolutivas semelhantes dos alunos. Essa foi uma forma de o professorpesquisador refletir sobre suas ações pedagógicas e compreender os acontecimentos existentes no decorrer da elaboração das oficinas-aulas, a fim de promover novas formas de mediação, adotando novos arranjos pedagógicos na dinâmica das aulas. A construção de brinquedos com material reciclável (garrafas de plástico, jornais etc.) em uma perspectiva da educação ambiental foi um caminho possível de conscientizar as crianças sobre conteúdos relacionados ao meio ambiente, articulando-se ao processo de aprendizagem, como princípio pedagógico, ao valorizar o lúdico e o educando em sua totalidade, pois:

\title{
[...] podem-se atribuir ao fenômeno social da aula o encontro e o confronto dos subúrbios (do senso comum e do conhecimento sistematizado), geradores de condições para a produção de múltiplos signos a respeito dos conteúdos ensinados (RODRIGUES JUNIOR, LOPES DA SILVA, 2008, p. 165).
}

Nas oficinas, a reciclagem dos materiais que indevidamente vão para o lixo, permitiu que eles fossem reutilizados na intenção de incentivar a criação e a transformação do material reciclável nas diversas formas possíveis e imagináveis de brinquedos. Após a realização das oficinas-aulas, foi feita a análise dos significados do brincar e da construção de brinquedos para as crianças, tendo como base o referencial teórico estudado, centrado nos estudos da Educação Física plural, da educação ambiental, da construção de brinquedos (material reciclável), do brincar e do lazer. A seguir, damos um exemplo de como ocorreu uma das oficinas-aulas.

\section{RESULTADOS E DISCUSSÃO}

\author{
Exemplo de uma oficina-aula
}

$\mathrm{Na}$ oficina-aula "A construção de brinquedos com material reciclável nas aulas de Educação Física", o objetivo foi: vivenciar e construir os brinquedos com material reciclável, visando ampliar o repertório de jogos e brincadeiras das crianças e, além disso, conscientizá-las sobre questões relacionadas ao meio ambiente.

Inicialmente, o professor reuniu as crianças da turma em círculo, interagindo com todas, perguntando se elas já tinham visto ou construído brinquedos com 
material reciclável. Algumas crianças disseram que sim, e outras, que não. $O$ professor explicou o objetivo proposto na atividade e deu orientações sobre a disposição dos materiais recicláveis, destacando a importância de reaproveitar materiais que são descartados e vão para o lixo, com a intenção de sensibilizar as crianças em relação ao consumo, à reciclagem e à preservação do meio ambiente. No espaço da oficina-aula, o professor apresentou os recursos a serem utilizados, tais como: garrafa pet, jornal, fita adesiva, bolinha de gude, tesoura, barbante e sacola plástica. As crianças ficaram interessadas e perguntaram para o professor como se construía brinquedos com materiais recicláveis. O professor explicou e demonstrou a todas as crianças as fases de como se construía o brinquedo (peteca), esclarecendo as dúvidas. Em seguida, as crianças foram organizadas em quatro grupos de sete pessoas, para que cada aluno construísse seu brinquedo e compartilhasse suas ideias trabalhando coletivamente com seus colegas, utilizando os materiais citados.

No decorrer da construção, algumas crianças comentavam sobre como realizavam suas ações na construção da peteca, e aquelas que tinham dificuldade solicitavam a ajuda dos colegas. O professor acompanhou de forma contínua todos os grupos, esclarecendo algumas dúvidas e auxiliando as crianças que tinham maior dificuldade e estimulando a criatividade das crianças. Além disso, trabalhou conceitos sobre o meio ambiente por meio do objeto criado, conscientizando as crianças: na construção da peteca, por exemplo, o reaproveitamento do papel minimiza os impactos ambientais causados com o seu descarte, uma vez que, ao perder sua função original, pode ser utilizado em outro contexto.

A peteca foi construída, em sua base, com uma folha de jornal amassada, colocada no centro de outra folha sobreposta, cujas pontas puxaram-se para cima. Um barbante foi utilizado para fixar ao meio as folhas de jornal que envolveu a folha amassada e lhe deram formato de bola na parte inferior. Uma sacola plástica foi usada para revestir a base com o auxílio de fita adesiva. As pontas de jornal foram cortadas em tiras de cima para baixo até o barbante, o que deu leveza ao objeto. 0 passo a passo de sua construção é demonstrado na figura 1, a seguir.

Figura 1 - Etapas da construção da peteca

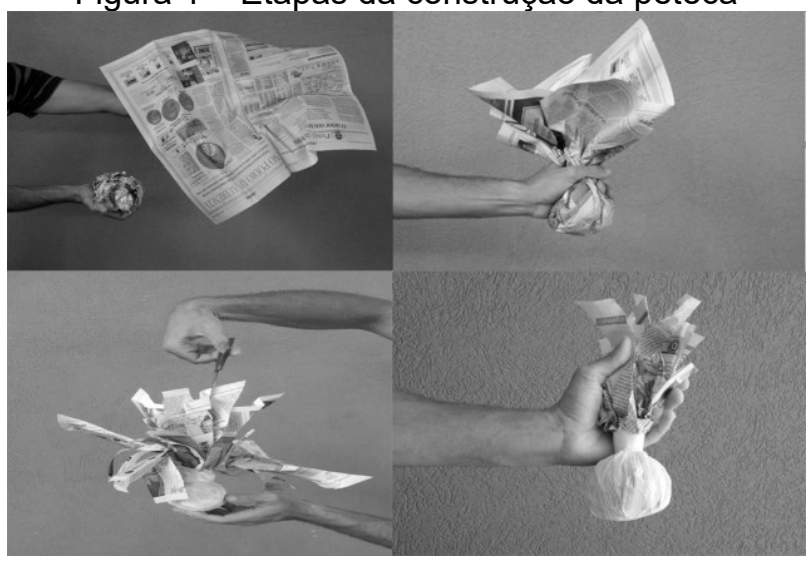


Quando todas as crianças finalizaram a peteca, foi proposta a construção do outro brinquedo, o cai-cai, elaborado com duas garrafas pet que foram convenientemente cortadas, sendo que, de uma delas, eliminou-se a base. A outra garrafa pet, cortada ao meio, foi afixada, com fita adesiva, na extremidade superior da primeira garrafa, em posição invertida, deixando-a com duas possibilidades de entrada. Uma de suas entradas, retirada a tampa, encaixou-se (também com fita adesiva) dentro da base da outra garrafa. Antes de fechar a garrafa alongada, inseriram-se bolinhas de gude. O objeto é apresentado pela Figura 2, logo abaixo.

Figura 2 - Etapas da construção do cai-cai

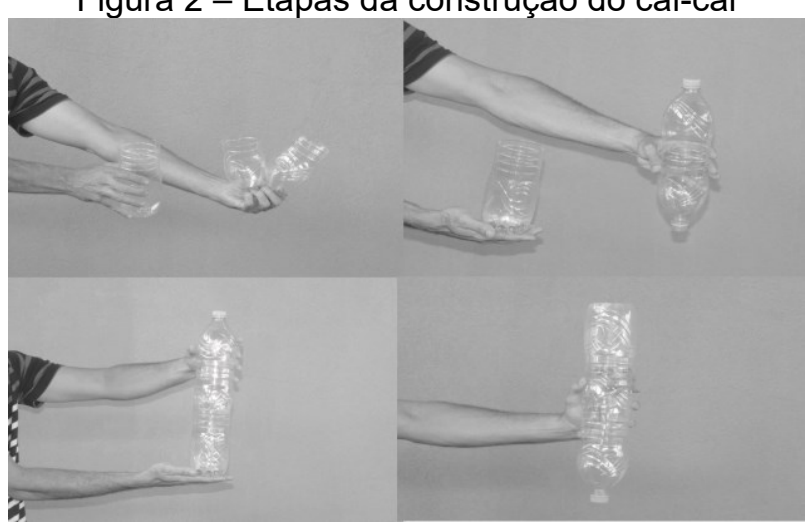

As crianças tiveram algumas dificuldades na construção do brinquedo cai-cai. No momento de fixar as partes da garrafa uma à outra, algumas relataram dificuldade e o professor fez algumas intervenções pedagógicas com elas, no intuito de solucionar os problemas apresentados. Além disso, orientou os alunos sobre a importância de reaproveitar a garrafa pet, devido à demora na sua decomposição no meio ambiente; se não for reciclada, pode trazer prejuízos à natureza. Ou seja, uma proposta abordada na perspectiva da educação ambiental tem como propósito conscientizar as crianças para o exercício da cidadania, possibilitando um olhar diferenciado em relação ao lixo que pode ser reutilizado. O professor, ao realizar suas ações pedagógicas na aplicação de atividades diversificadas para crianças por meio de oficinas-aulas, utilizando material reciclável para a construção de brinquedos, possibilitou a oportunidade de a criança vivenciar ações que podem ser aliadas à fantasia e à realidade concreta, desenvolvendo autonomia, criticidade, e construindo conhecimento com relação ao cuidado com o meio ambiente.

Com relação à peteca, as crianças confeccionaram-na sem maiores problemas. Já na construção do cai-cai, algumas crianças tiveram dificuldade e solicitaram a orientação do professor e de alguns colegas. Após essa atividade ministrada pelo professor, foi sugerida às crianças a exploração dos brinquedos (peteca ou cai-cai) que elas haviam construído, ocasião em que poderiam brincar na quadra, sozinhas ou com um de seus colegas, de acordo com seu interesse.

Alguns alunos brincaram sozinhos, outros com seus colegas. Alguns meninos não queriam brincar com as meninas, mas o professor conversou com todos $\mathrm{e}$ 
enfatizou a importância de brincar de uma forma cooperativa socializando-se com os outros. Algumas crianças brincaram em grupo, jogando umas com as outras. Outras crianças optaram por utilizar o cai-cai, já que estavam concentrados o tempo todo, sem desviar o olhar, interagindo com o brinquedo, buscando, em alguns momentos, acelerar o movimento para que as bolinhas caíssem mais rápido na parte de dentro da garrafa, divertindo-se com a situação. Huizinga (2010) destaca que a realização do lúdico se dá no jogo, que tem sua intencionalidade no divertimento, na alegria, no prazer e no agrado.

A proposta dessa oficina-aula, ao promover o interesse da criança em uma visão ampla da realidade, no sentido de conscientizar o cidadão ao tratar o lixo de forma diferente para amenizar os problemas por ele causados, por meio da reciclagem na transformação de brinquedos, ou seja, encarar os materiais não como lixo, mas como materiais recicláveis, criando-se novas ideias. Ao terminar as atividades, o professor solicitou que as crianças organizassem a quadra, recolhendo restos de jornal, garrafas pet etc., para descartá-los no lixo reciclável da escola, e informou para as crianças que poderiam levar os brinquedos para casa e brincarem no seu tempo de lazer. A intenção do professor foi de incentivar as crianças a ter em casa brinquedos recicláveis, para brincar no seu tempo disponível, assim, os conceitos e conhecimentos aprendidos na escola podem ser estendidos no cotidiano da criança. Ao término da oficina-aula o professor fez intervenções com as crianças e os questionamentos da pesquisa: Vocês gostaram de brincar? Se sim, por que vocês gostaram? Se não, por que não gostaram? Vocês gostaram de construir brinquedos com material reciclável? Se sim, por que vocês gostaram? Se não, por que não gostaram? A seguir, apresentamos as respostas das crianças e a análise de tais respostas.

Os significados da construção e do brincar com brinquedos recicláveis para os alunos participantes

Quando questionados se gostaram ou não de brincar e de construir brinquedos, as crianças deram respostas como a que segue:

"Sim, por causa qui, tipo, você está brincando com um brinquedo novo, só que feito, tipo, foi você que fez, faz com material reciclável" (Aluno 13).

Ao analisarmos o comentário do aluno 13, sobre o brinquedo novo, pode-se interpretar que a atividade da aula fugiu ao convencional; ele está manifestando seu interesse pela novidade que lhe é apresentada. Observa-se que sua percepção atentou ao caráter experimental das oficinas-aulas. Podemos destacar o aspecto positivo do fato de que o aluno tem noção do caráter de imprescindibilidade da sua participação. E quando o brinquedo é feito pelo aluno com material reciclável, notase que é uma alternativa viável, sendo possível ampliar a diversidade de opções de jogos, de brincadeiras a qualquer indivíduo e também uma experiência para novas atitudes e o respeito ao meio ambiente (reciclagem, preservação e consumismo). De acordo com Campos e Mello (2010), o professor, ao proporcionar aos seus alunos 
ações pedagógicas com o propósito de construir seus próprios brinquedos, incentiva a sua criatividade e o seu desenvolvimento. Assim, o aluno é protagonista da ação, já que as crianças atribuem aos brinquedos artesanais um conjunto de significados. Segundo Oliveira (2010), o aluno artesão refuta a posição de sujeito passivo da ação, assume a condição ativa de construtor do cenário cultural, identificando criador e criatura nos objetos-brinquedos de sua fruição. Outro aluno destaca:

"Sim, porque estes brinquedos, a maioria é feito com recicláveis" (Aluno 9).

Weiss (1997) ressalta que, na construção de objetos criados a partir de material reciclável, é possível vivenciar experiências diversas, mas sua essência é a mesma: ampliar o repertório de pesquisa dos alunos, recuperando e valorizando o elemento lúdico e experimental por meio das brincadeiras. Huizinga $(2010, p .16)$ resume as principais características do jogo, destacando-o como "[...] uma atividade livre, conscientemente tomada como não-séria e exterior à vida habitual, mas ao mesmo tempo capaz de absorver o participante de maneira intensa e total". É uma atividade em que não se visa a nenhum interesse material ou financeiro, e, nela, o sujeito é compreendido por uma visão totalitária, respeitando uma ordem e certas regras, características da ação, o que promove a interação entre diferentes culturas.

A atividade lúdica na infância, além de propiciar o prazer, aumenta a motivação, a experiência enriquecedora da realidade, envolve emoções, promovendo a participação crítica e criativa em relação ao contexto social. A construção de brinquedos com material alternativo possibilita reaproveitar o que virou lixo e, com isso, podemos conscientizar as crianças a buscarem soluções para minimizar o impacto gerado pelo lixo, por meio da reciclagem, e também valorizar o brincar com o brinquedo construído, porque, acima do valor material do brinquedo, estão os conceitos que vêm da prática de inventar, criar, ter acesso ao produto e o reconhecimento do próprio trabalho realizado. Ou seja, a proposta da Educação Física escolar integrada com a educação ambiental visa encontrar formas de desenvolvimento nas crianças por meio de ações pedagógicas que atendam às necessidades da atualidade sem comprometer as gerações futuras.

De acordo com Oliveira (2010), o exercício da fantasia na infância é uma possibilidade de liberação da sua imaginação, para que seus desejos se manifestem e se realizem no seu contexto. Esta constitui uma ação prática efetiva que se torna relevante para as crianças se expressarem por meio de um processo espontâneo e infinito. A capacidade de inventar é maior das crianças, por sua sensibilidade diante das coisas de acordo com a sua realidade. Para Machado (2003), a criança que brinca está não só explorando o mundo ao seu redor, mas também comunicando sentimentos, ideias, fantasias, intercambiando o real e o imaginário num terceiro espaço, o espaço do brincar e das futuras atividades culturais. "Brincar é viver criativamente no mundo. Ter prazer em brincar é ter prazer em viver" (MACHADO, 2003, p. 27). Por meio do brincar, a criança obtém a satisfação de criar. Na vivência da brincadeira, a criança e o brinquedo se vinculam de tal maneira que, naquele contexto, em determinado momento, há proximidade entre o sujeito e o brinquedo, tornando-se um só. As atividades desenvolvidas nas oficinas-aulas possibilitaram 
uma experiência rica de construir brinquedos com material reciclável, brincar com eles, reutilizar materiais que teriam o lixo como destino, proporcionando uma aprendizagem significativa para às crianças, visando formar sujeitos ativos, responsáveis e conscientes. Outro aluno afirmou:

"Sim, porque dá para fazer várias brincadeiras com este tipo de brinquedo" (Aluno 17).

De acordo com Meirelles (2007), o brincar desenvolve a criatividade e a socialização entre os alunos, promovendo a capacidade de improvisar, inventar e reconhecer o valor de cada espaço disponível para a brincadeira, preservando a atividade, visto que potencializa o lúdico, tornando-se essencial para alimentar a infância. As crianças, ao usufruírem da sua criatividade, quando exploram os diversos espaços, criam uma variedade de brincadeiras, brinquedos ou jogos, dão vida à fantasia, à imaginação, na utilização de objetos ou de vários recursos. Cavallari (2013) relata que a aula de Educação Física, ao oferecer aos seus alunos diferentes atividades da cultura corporal de movimento, não se restringe apenas a um dos seus conteúdos, mas os diversifica, abordando temáticas de relevância social. A Educação Física escolar articulada com outras disciplinas (Português, Ciências, Sociologia, Filosofia), em uma perspectiva interdisciplinar visando à educação ambiental, constitui-se em uma ação pedagógica com o intuito de mobilizar saberes na abordagem de conteúdos (consumo, reciclagem, preservação) tão importantes para a formação das crianças, como novas atitudes, novos valores e noções de cidadania. Assim, é essencial uma mudança na mentalidade do cidadão na atualidade, com o intuito de ampliar a visão das crianças sobre os problemas cotidianos, relacionados ao meio ambiente, e simultaneamente uma modificação de hábitos imediatamente, visando ao bem-estar das pessoas. Outro aluno relatou:

"Sim, por causa que os brinquedos são recicláveis e muitos eu não conhecia" (Aluno 9).

Ao analisarmos a resposta do aluno 9 foi possível observar que as aulas que introduziram brinquedos com material reciclável, provocaram emoção no aluno ao se reconhecer como aprendiz do brincar. Este mesmo aluno 9 foi surpreendido pela novidade apresentada pelos brinquedos novos. Constatamos, ainda, que, além de os brinquedos "recicláveis" serem desconhecidos por este e outros alunos, a oficinaaula revelou ao professor-pesquisador o espírito crítico que alguns deles expressaram pelo "diferente" da situação. Os brinquedos, construídos com material reciclável, utilizados pelas crianças na oficina-aula, possibilitam o encontro com uma cultura diferente, à qual muitos não têm acesso ou não tiveram a oportunidade de vivenciar. Assim, nos identificamos com as ideias de Vago (2009), sobre a escola ser um lugar privilegiado entre as culturas, visto que se relaciona com outros lugares em que pessoas produzem cultura: nas ruas, nas praças, dentre outros. Valorizar a cultura no ambiente escolar para os alunos a partir dos brinquedos recicláveis promove o compartilhamento de diferentes culturas, tornando o ambiente enriquecedor para quem nele vivencia experiências. Segundo Daolio (1997), a Educação Física deve não só dar conta da pluralidade de formas da cultura corporal humana (jogos, danças, esportes, ginásticas e lutas), como também da expressão diferencial dessa cultura nas suas aulas. Ou seja, podemos destacar uma prática 
escolar sem preconceitos em relação à cultura corporal dos educandos, propiciando a todos o acesso a uma Educação Física igualitária. Outro aluno comentou:

\footnotetext{
"Sim, é porque, assim, é cada vez a gente aprende mais brinquedos e também tem muita gente que só fica no celular e não conhece esses brinquedos" (Aluno 6).
}

Analisando o comentário do aluno 6, notamos que, nas aulas de Educação Física, as atividades lúdicas desenvolvidas no contexto escolar favorecem a descoberta da variedade de opções para brincar, promovendo uma aprendizagem significativa para os alunos. Segundo Meirelles (2007), um gesto simples ou um olhar pela criança convida a outra a brincar, basta existir esse encontro que desperta a vontade para compartilhar diversas brincadeiras. A mesma autora comenta que essas características garantem a existência da brincadeira em qualquer parte do mundo, seja nas cidades, nos pequenos vilarejos ou em outros espaços, é só deixar as crianças se encontrarem. $\mathrm{Na}$ atualidade, as crianças brincam junto com as outras com uma variedade de brincadeiras do passado de uma forma diferente, influenciadas pela sua cultura, ou seja, acompanham as mudanças culturais que acontecem no decorrer dos tempos. De acordo com Vago (2009), a Educação Física tem potência para ser um tempo de fruir, de usufruir, de viver e de produzir cultura. Ou seja, constitui um espaço de enriquecimento da experiência humana, possibilitando práticas afetivas, lúdicas e estéticas de aprender e de compreender o mundo e de nele agir. A experiência de jogar e brincar com variedade de jogos na rua, na escola, em casa e em outros espaços, possibilita a interação com diversos tipos de jogos, conhecendo outras ou novas culturas, ampliando seu acervo e dando abertura à diversidade em todas as manifestações socioculturais. Outro aluno mencionou sobre o quê gosta de fazer no seu tempo disponível:

"Eu faço o virtual e esportes, porque são divertidas, eu adoro dançar, correr" (Aluno 23).

Ao analisar o comentário do aluno 23, observa-se que no seu tempo disponível o jogo virtual é vivenciado de uma forma intensa e prioritária no seu tempo de lazer, embora este mesmo aluno tenha comentado que fazia dança, ou seja, foram mencionados como opções pelo educando. Com o desenvolvimento tecnológico na atualidade, os recursos eletrônicos, cuja aquisição é incentivada, ou mesmo instigada pelo consumismo, pode-se dizer que eles permeiam a rotina das pessoas, com nítido predomínio na atualidade, o que influencia a complexidade da formação do ser humano. Entretanto, nos dias atuais, as brincadeiras populares estão sendo substituídas por brinquedos tecnológicos: vídeo games, computadores, tablets, televisão e celulares. O reviver das brincadeiras "esquecidas" se faz necessário para que a criança tenha acesso ao saber popular. Benjamim (2002) comenta que, o brinquedo tem sido visto como criação para a criança e, quando não, como criação dela. As crianças, no ato de brincar, são produtoras de brinquedos, visto que, na brincadeira, transformam cabo de vassoura em cavalo, uma simples pedra vira uma moeda, entre outras. Dessa maneira, podemos dizer que a criança transforma qualquer objeto em brinquedo, ou seja, aquilo que está ao seu alcance e que é relevante para o desdobramento da atividade lúdica. Ampliar a visão das crianças sobre as opções no seu tempo de lazer pode favorecer múltiplas alternativas no tempo disponível, já que o sujeito pode ter mais que uma opção de 
escolha das atividades desenvolvidas no contexto do lazer. Para Marcellino (2007) um processo de incentivo ao espírito crítico, em que a educação para o lazer a partir das aulas de Educação Física escolar não cria necessidades, mas visa a satisfazer necessidades individuais e sociais.

Tudo isso representa um conjunto de ideias que trazem um diferencial contendo subsídios ao trabalho cotidiano do professor de Educação Física no seu cotidiano de aulas. Sendo assim, potencializar ações pedagógicas no ambiente escolar utilizando material reciclável é essencial no desenvolvimento da criança, promovendo uma visão ampla da realidade que só a ação de fazer é capaz de desenvolver.

Todas as crianças afirmaram ter gostado das brincadeiras propostas e também de construir seus próprios brinquedos. Muitos não conheciam ou fazia muito tempo que não brincavam com brinquedos construídos com materiais recicláveis, restringindo-se a outras atividades ou jogos eletrônicos no seu tempo disponível. Os brinquedos construídos eram desconhecidos por muitas crianças, e quanto à característica de o objeto ser "reciclável", as crianças valorizaram o fato de se utilizar um recurso diferente para que pudessem brincar e também aprender sobre questões relacionadas ao meio ambiente (consumo, preservação, reciclagem).

Percebemos que a vivência do brincar pelas crianças nas oficinas-aulas foi uma ação desafiadora para elas, sendo que o elemento lúdico foi predominante em todo o processo pedagógico.

Observamos também que as crianças, ao construírem seus brinquedos, demonstraram satisfação pelo ato de criar, assim como pela liberdade de se expressar. As crianças gostaram de brincar pelo fato de serem brinquedos construídos com materiais recicláveis, pela construção ter sido feita por elas, pelas experiências sobre a importância de respeitar o meio ambiente e pela possibilidade de várias brincadeiras serem realizadas com os brinquedos construídos.

\section{CONSIDERAÇÕES FINAIS}

Esta pesquisa teve como objetivo analisar os significados do brincar e da construção de brinquedos para crianças do Ensino Fundamental em uma situação planejada de oficina-aula de construção de brinquedos com materiais recicláveis, em uma perspectiva de educação ambiental. Considera-se a Educação Física uma área de conhecimento que busca desenvolver seus saberes, permitindo-se um campo amplo de atuação, articulando-se com a educação ambiental, podendo viabilizar ações integrativas ao conscientizar as crianças sobre o meio ambiente por meio de atividades diversificadas. Todavia, cabe ao professor o papel de conscientizar as crianças sobre as questões ambientais, viabilizando uma ação pedagógica contínua de acordo com o contexto escolar, desenvolvendo o pensamento crítico e a consciência global no sujeito por meio da temática ambiental. 
$\mathrm{Na}$ dinâmica das oficinas-aulas, consideramos que as crianças se socializaram com a dinâmica proposta em forma de estações (circuito), que potencializou nelas a oportunidade de brincar, juntamente com orientações sobre a construção de brinquedos com material reciclável. Utilizaram-se também materiais diferentes, não convencionais, promovendo uma experiência enriquecedora e atrativa para quem participou. Identificamos, durante as oficinas-aulas, pontos relevantes manifestados pelas crianças: a alegria de ter acesso a outros tipos de brinquedos, jogos, atribuindo-lhes um conjunto de significados e reconhecendo a cultura do próximo. A ampliação de vivências motoras, contemplando a diversidade cultural dos participantes nas oficinas-aulas possibilitou uma aproximação com a Educação Física Plural. A experiência de construir brinquedos recicláveis visou oportunizar outras opções de jogos surgindo como alternativa diversificada de práticas lúdicas, gerando novas experiências entre as crianças sobre o brincar, e também a conscientizar os alunos sobre ações que podem ajudar no cuidado com o meio ambiente, ou seja, ações criativas e lúdicas com o propósito de despertar atitudes e valores de responsabilidade social nas crianças em respeito à natureza.

Entendemos que a Educação Física escolar pode contribuir e sensibilizar as crianças a se familiarizarem com a construção de seus próprios brinquedos artesanais e com eles brincar, promovendo a autonomia, a criatividade e a criticidade na adoção de valores que tencionem atitudes consumistas e individualistas dos sujeitos. No entanto, é fundamental também que as instituições de ensino disponibilizem para as aulas de Educação Física, os materiais tradicionais - bolas, arcos etc., já que compreendemos que o professor, ao ter acesso aos diferentes materiais tradicionais ou recicláveis, poderá ter maiores opções para a elaboração de suas aulas e, consequentemente, estas poderão ser mais enriquecedoras para as crianças.

Esperamos, que esta investigação possa contribuir para outros estudos e experiências relacionadas, e que os professores considerem os estudos da Educação Física, o lazer, o lúdico e a educação ambiental na elaboração de suas aulas, de modo que os conhecimentos sobre a construção de brinquedos, a conscientização sobre o meio ambiente e o brincar podem e devem ser acessíveis a todos.

\section{REFERÊNCIAS}

Benjamin W. Reflexões sobre a criança, o brinquedo e a educação. 1. ed. São Paulo: Editora 34; 2002.

Bruyne P, Herman J, Schoutheete M. Dinâmica da pesquisa em ciências sociais: os pólos da prática metodológica. 5. ed. Rio de Janeiro: Francisco Alves; 1991.

Campos D A., Mello M A. As linguagens corporais e suas implicações nas práticas pedagógicas: brinquedos, brincadeiras, jogos, tecnologias, consumo e modismos. São Carlos: EdUFSCar; 2010. 
Carvalho I C M. A invenção do sujeito ecológico: sentidos e trajetórias em educação ambiental. Porto Alegre: EdUFRGS; 2001.

Castro R S, Layrargues P P, Loureiro C F B. Repensar a educação ambiental: um olhar crítico. São Paulo: Cortez; 2009.

Cavallari T A. Lazer e educação física nas propostas curriculares de ensino fundamental e médio do estado de são paulo. In: Marcellino N C (Org.). Lúdico, Educação e Educação física. 4. ed. ljuí: Unijuí; 2013. p. 197-205,

Daolio J. Da cultura do corpo. 2. ed. Campinas: Papirus; 1994.

Daolio J. Cultura: educação física e futebol. Campinas: Editora da UNICAMP; 1997.

Huizinga J. Homo Ludens: o jogo como elemento da cultura. 6. ed. São Paulo: Perspectiva; 2010.

Lopes da Silva C. Mediação de sentidos: aulas compartilhadas no Brasil e em Portugal junto a estudantes de Educação Física [Tese (Doutorado em Educação Física)]. Campinas: Universidade Estadual de Campinas; 2008. [Acesso em: 19 mar. 2018]. Disponível em:

http://www.bibliotecadigital.unicamp.br/document/?code $=000435752 \& f d=y$

Lucentini L A. A temática ambiental como proposta para aulas de Educação Física na $4^{a}$ série do ensino fundamental. [Dissertação (Mestrado em Educação Física)]. Piracicaba: Universidade Metodista de Piracicaba; 2010.

Machado M M. O brinquedo-sucata e a criança. São Paulo: Loyola; 2003.

Marcellino N C. Lazer e Educação. 12. ed. Campinas: Papirus; 2007.

Meirelles R. Giramundo e outros brinquedos e brincadeiras dos meninos do Brasil. 3. ed. São Paulo: Terceiro nome; 2007.

Minayo M C S. Pesquisa social. 21.ed. Vozes, Petrópolis RJ; 1994.

Oliveira P S. O que é brinquedo. 3.ed. São Paulo: Brasiliense; 2010.

Pinto L M S M. Lazer e educação: desafios da atualidade. In: Marcellino N C. (Org). Lazer e sociedade. Campinas: Alínea; 2008.

Oliveira W F, Alvim M P B. Educação Física e educação ambiental: como trabalhar no âmbito escolar? Movimentum, Revista Digital de Educação Física, Ipatinga. 2009 ago./dez.; 4(2). [Acesso em 2018 jul. 20].Disponível em:

https://www.unileste.edu.br/movimentum/Artigos_V4N2_em_pdf/Oliveira_Alvim_Mov. 2_2_2009.

Rodrigues Junior J C, Lopes da Silva C. A significação nas aulas de Educação Física: encontro e confronto dos diferentes "subúrbios" de conhecimento. ProPosições, Campinas. 2008; 19(1):159-172. 
Schwartz G. M. O imaginário criativo em jogo. Revista Brasileira de Ciências do Esporte, Campinas1992; 12(1, 2, 3):318-319.

Severino A. J. Metodologia do trabalho científico. São Paulo: Cortez; 2007.

Vago T. M. Pensar a educação física na escola: para uma formação cultural da infância e da juventude. Cadernos de Formação RBCE. Campinas. 2009; 1(1): 25 41. [Acesso em: 2018 set. 22]. Disponível em:

http://www.rbceonline.org.br/revista/index. php/cadernos/article/viewFile/930/540..

Weiss L. Brinquedos e engenhocas: atividades lúdicas com sucata. São Paulo:

Scipione; 1997.

\section{Agradecimento}

Agradecemos à Secretaria da Educação do Estado de São Paulo (SEE/SP) pelo financiamento da pesquisa.

Artigo recebido em: 26/11/2018

Artigo aprovado em: 10/09/2019

Artigo publicado em: 16/09/2019 